\title{
Enriching Aboriginal Engagement in Schools through Service-learning: The Biidaaban Experience
}

\author{
Blaine E. Hatt (Ph. D). \\ Schulich School of Education \\ Nipissing University \\ Nancy Maynes (Ed.D.) \\ Schulich School of Education \\ Nipissing University
}

Received: April 3, 2017 Accepted: May 12, $2017 \quad$ Published: May 12, 2017

doi:10.5296/jse.v7i2.11194ＵRL: https://doi.org/10.5296/jse.v7i2.11194

\begin{abstract}
This paper involves an inquiry into the effects and affects of service learning in a Biidaaban Youth Group (BYG) programme under the auspices of the Biidaaban Community Service Learning centre (BCSL) at a small northern Ontario university. Phenomenological, hermeneutical, and narrative inquiry approaches were applied to interviews with stakeholders in BYG including a First Nations' parent, a school-aged child, a First Nations' grandparent and Elder, an education community partner, and a university-student tutor. The concepts of pathic teaching and liberatory service learning help to frame the findings of this study. Analysis of the data evidenced authentic caring for self and other and genuine reciprocity that is transformative and enabled participants to attain a liberatory level of social change and social consciousness as key components of the high quality of service learning that is perceived by those who serve and those who receive service from this unit.
\end{abstract}

Keywords: community service learning, attending the pathic, peak experiences, transformative learning, liberatory service learning 


\section{Introduction}

The Biidaaban Community Service Learning (BCSL) programme began at a northern Ontario university during the last decade with a generous donation from a family foundation. Biidaaban, pronounced bee-daw-bun, in the Ojibwe (Anishinaabe) dialect refers to the point at which the light touches the earth that heralds the dawning of a new day. The BCSL programme was conceived as the dawning of new learning for post-secondary students and as an illumination of learning for school-aged students. It is also conceived as the rise of a successful course-based service-learning program that marks the beginning of a life-enriching volunteer partnership among university students, community organizations, and Aboriginal groups. While the full radiating effects of Biidaaban and BCSL are yet to be realized, it is nevertheless a programme complete with its attendant sub-programs that has generated a service-learning focus within the university and its community partners that is worth highlighting and worth celebrating.

One such programme offered under the umbrella of Biidaaban Community Service Learning is the Biidaaban Youth Group (BYG). This initiative was established in partnership with the local school board district. Its main goal was to enhance the educational experiences of a growing population of First Nations students in district elementary and secondary schools. Within those school settings, there are two distinct First Nation groups: urban First Nation students, from the region, who have English as a strong component of their home language base and English Language Learner (ELL) First Nation students from distant communities whose first, and in many cases only language, is Cree or a dialect thereof.

The Biidaaban Youth Group (BYG) is housed in neighbourhood schools with a high population of First Nations students and is offered between 3:00-5:00 pm twice a week for eight weeks in the fall session and eight weeks in the winter session of the University Academic year. The target group is children or youth of First Nation and Aboriginal parents who are attending post secondary studies at the university and community college, as well as First Nation or Aboriginal children or youth of the district school board. Enrollment and participation in BYG is voluntary and attracts First Nations and Aboriginal students who want or need tutoring assistance in completing homework, who have a desire to interact with other children or youth, and who like to participate in fun activities.

The programme is run by a program leader and three university students who complete a general orientation to community service-learning, group sensitivity training and cultural awareness of First Nation and Aboriginal peoples, and, actively participate in four debriefing sessions (two per term) during the academic year. These orientations are provided by the Biidaaban Community Service Learning (BCSL) center at the university. End of programme celebrations are held and typically include a pizza party and a visit to the University main campus for university students (tutors), programme leader(s), children and/or youth, and community partners. 


\section{BCSL Annual Reports and the Impetus for this Study}

Annual reports about the BCSL programmes were written to focus readers' attention on the various opportunities the programme provided to advance student learning and engagement and to support community improvement (Friere, 1970; Kolb, 1984). While Eyler and Giles (1999) identify deeper understanding of self as a goal for service-learning when structured reflection aids students' efforts to internalize understandings, unfortunately, none of the BCSL annual reports featured student-participant reflections. Much of the content in the reports dealt with demographic elements of the programme such as: numbers of people involved, various locations in which the programme was located, and, anecdotal, summative, comments on the benefit of the programme to university students, university faculty, First Nations leaders, school-aged children, First Nations partners, and community partners.

These annual reports did not employ critical inquiry to examine participants' experiences or focus on the deeper understandings of concepts or issues related to community and society (Van Wynsberghe \& Andruske, 2007; Borozangi, Greenwood, Burns \& Finnie, 2003; Reardon, 1998; Schutz \& Ruggles, 1998; Weinburg, 2003; Weichman, 1996). Chambers (2009) posits a four-level framework of the potential of service-learning experiences on participants: experiential learning, social learning, student development, and liberatory education. However, past reports, in general terms, emphasized the significance and importance of relationships between and among service-learning participants and partners in extending the personal skills of the students through unique experiences (Bringle \& Hatcher, 1996) consistent with a theory of social learning (Bandura, 1977) but on the lower end of the spectrum of possible outcomes as proposed by Chambers. Beyond a focus on social learning, the annual reports did little to inquire into the actual effects and affects of service-learning on those directly and indirectly associated with the programme.

Our research focused on the question "What is it to experience Biidaaban Community Service Learning; specifically Biidaaban Youth Group (BYG)?" This study is one attempt to address the shortcoming of the previous approaches to annual reports for this initiative. The five individuals interviewed for this study were recommended by the Director of the Office of Aboriginal Initiatives and included: a parent with two chidren enrolled in BYG, a grandmother and Elder with a grandaughter enrolled in BYG, a school adminsitrator with BYP running in her elementary school, a student enrolled in BYG, and a university student serving as a BYG faciliator/tutor. We applied phenomenological and hermeneutic inquiry approaches to the deep interviews that we conducted with the identified stakeholders associated with the Biidaaban Youth Group programme. Each interview employed a set of question-prompts focused on impacts before, during, and after the service-learning experience and were designed essentially to elicit the lived-experiences (van Manen, 1990) which can reveal the rich tapestry of being in relation to self and other (Buber, 1970; Levinas, 1993; Gadamer, 1975); attending the pathic (Hatt, 2008); and, being-in-the world (Heidegger, 1927). 


\section{Methodology}

The participants in this study were asked to engage individually in an interview for the purpose of gathering information that would hopefully strenghten the Biidaaben Community Service-Learning project and in particular the Biidaaban Youth Group programme. Participant anonymity was a characteristic of this study and was safeguarded in an agreement between the researcher(s) and the individual participants. Other than child to parent and parent to child, participants would not know the identity of other participants. The full anonymity of all participants and the partial anonymity of child/parent relationships were verbally explained to each participant prior to gaining their consent to participate in the unstructured interview process.

Each interview was conducted in a relaxed, semi-structured format in order for interviewees to contemplate and communicate their BYG experience(s) in as much detail and as effortlessly as possible. The interviews were recorded, transcribed, and reviewed by the respective interviewee for accuracy before data analysis commenced. Particiapnts were asked to recount in detail their thoughts, feelings, and impressions of BYG in four clusters: before entering the programme; during the programme; after leaving the programme; and, their most memorable BYG lived-experience. Question-prompts were employed in a collegial, interactive process during the interviews in order to minimize hierarchical relationships and to maximize the evocation of meaningful, personalized, lived experiences (Kvale, 1996). For example, the question prompts for during the programme were:

1) What surprised you most, and least, upon entering the BYG programme?

2) What challenges or successes did you face while in the BYG programme?

3) How was the BYG programme benefitting you while you were enrolled in the programme?

4) If you could, what would you do differently, do the same in BYG? Why?

5) Can you describe in detail your thoughts, feelings, and impressions of an experience that you had while enrolled in the BYG programme?

A similar set of question prompts was used to determine each participant's perspective before entering the programme and reflection(s) after completing the programme. The prompt to elicit a memorable lived-experience(s) was:

In detail, describe the BYG experience that most impacts you as a participant in the program. If the experience involves conversation with another or others, give the dialogue as accurately as possible. In your telling, use the "I" voice, in the present tense, or as the experience is happening rather than as it happened. In other words, decribe in detail: What is it to experience BYG?

Transcripts were made of each interview, vetted with the interviewee, and then submitted to the rigors of critical, phenomenological, hermeneutical, and narrative analysis. The responses to each of the four clusters were analyzed separately using a thematic approach documented by van Manen (1997). Clusters were individually and comparatively examined to identify 
content. The content was subdivided into categories and further divided into themes. The themes that emerged were several, varied, and were appropriately coded (Strauss \& Corbin, 1998) using the N-VIVO 8 Software program (QSR), a computer-assisted data management tool. Categories, themes, and codes were then linked in a comprehensive phenomenological, hermeneutical, and narrative interpretation of the research question.

\section{Results}

Pascarella and Terenzini (2005) posit three broad categories or end-results for those actively engaged in service-learning: educational, vocational, and social. While these categories are somewhat reflective of the Chambers categories (2009), there are also significant differences related to long-term views of outcomes on the worldviews of those who serve, which is characteristic of Chambers' liberatory level of service. Analysis and coding of the themes of the interviews were conducted. For example, there was a strong awareness of societal disparities, of learning through service, of personal growth, of intentions to continue service to others, and of a developing sense of personal efficacy when working with differences, that emerged and re-emerged in the interview data.

These finding supported a quantitative study conducted by Maynes, Hatt \& Wideman (2011) which found that pre-service teachers involved in a four-week service-learning practicum achieved the first three levels within Chambers (2009) framework (experiential learning, social learning, and student development) but not the fourth level (liberatory education). Specifically, in the experiential level of service-learning, the participant is less engaged with those being served and takes an observer role. In social learning, the focus is on what the participant takes from the experience by learning about other social conditions in the larger community. In the student development level of service-learning, the participant is concerned with expanding his/her own skill set. Reciprocity is the hallmark of the fourth level, the liberatory approach. It is here that the participant and the community partner both give and get service. The researchers in the Maynes et al. study concluded that the post-questionnaires completed by each pre-service teacher and respective supervisors did not include evidence of the structured reflection (Eyler \& Giles, 1999) that is required to aid pre-service teachers' efforts to internalize new understandings evident in liberatory approaches to service-learning.

Extended semi-structured interviews allowed participants in our study a safe place, a safe space and opportunity to reflect and to give voice to their lived experiences of BCSL. This had the immediate benefit of evoking detailed accounts as they were happening within the Biidaaban Community Service Learning programme as opposed to as they had happened. Participants were able to make tacit knowledge explicit through narrating their experiences (Astin \& Sax, 1998; Pace, 1979, 1984; Ethington \& Horn, 2007) thereby revealing the social transformation (Chambers, 2009; Green, Eckel \& Hill, 1998) that had occurred within them as evidenced by the deeper themes of authentic caring for self and other (Noddings, 1984; Heidegger, 1927) and genuine reciprocity.

Being with others, having concern for others, and taking care of others within their life-world were modes of being that were expressed by five of the six participants in our study. One participant expressed experiences that transcended the outcomes of community 
service-learning as categorized by Pascarella and Terenzini (2005) and who, as a direct consequence of her positive relationality with students in BYG. transcended self-actualization of social change and social consciousness through service-learning and attained what Maslow (1964) referred to as peak experiences or that Chambers (2009) refers to as liberatory service-learning. Her lived experiences will be discussed later in this paper.

Investigating the lived experiences of the five remaining participants in the study provided the researchers with an opportunity to examine recounted experiences and to discern the difference(s) between parenthetical knowledge and experiential knowledge. The data collected from these participants identifies themes that are potentially reciprocal and transformational. Such findings combined with the data obtained from the direct participants in the BYG programme, add to the growing canon of literature focused on service-learning and point to the viability of qualitative research in examining lived-experiences of participants involved in achieving the highest levels of community service -learning outcomes.

\section{The Biidaaban Youth Program was there for them ... they needed it!}

Mary is a full-time university student and the mother of two boys who participated in the Biidaaban Community Service Learning BYG programme. She and her family traveled from a remote Northern Ontario community in order for her to attend University. Adjustment to a new community, to a new school, and to a new culture was difficult for her and her children. Mary (pseudonym) and her boys speak Cree as their first language of communication. In answer to the question "What prompted you to become part of the Biidaaban Youth Group program?” Mary replied:

My children, I allowed them to participate in the programme, because I know how scary it is to be around people that are not aboriginal themselves. I know how uncomfortable it is. I'm sure that they felt intimidated by the language, because that was my challenge. I wasn't intimidated by the, I want to say, you know white, white people. I was intimidated with the English language and I wanted them to be more comfortable in their own skin and how they present themselves, and, I thought that would help, because I didn't have that. I had to do it on my own.

There are several themes emergent in Mary's reply. There is a strong maternal instinct to protect her children and to shield them from potential harm. There is a strong sense of emotional transference. Mary's emotive responses to intimidation, fear or discomfort are ascribed to her children based on her own personal experience(s): "I'm sure that they felt intimidated by the language, because that was my challenge."

English as a language is the medium for basic communication and expression of ideas, feelings, emotions, and on a deeper level the values of the dominant society or culture in Canada (Schubert, 2010). The English language can serve to exile the novice English Language Learner as it excludes her/him from participation in the dominant culture. It can act in its multifarious forms as oppression and in its cruelest use can act as a form of linguistic or 
cultural genocide. Language, in its structures, can be colonizing as Mary revealed in her interview.

I know when I studied it [the English language] it took me longer than most of my classmates because when I read something and I didn't understand what one...one word would throw me off, I would have to go to a dictionary and look it up and if the dictionary gave me gibberish, I would have to go to another dictionary. But [it wasn't just] my struggle with the language. I wasn't ... it's the way they [speakers of English] would reverse it, ... like if I say something in Cree in a sentence, it's so different in English, because it's the other way around. And, every time a classmate would come up to me and talk to me, I wouldn't want to talk to them. My face would turn red because I was uncomfortable speaking English. I felt embarrassed. Like I didn't want them to think I was stupid or anything, which I felt most of the time.

Not surprisingly, Mary wanted to spare her children the linguistic and cultural exile that she experienced so deeply. However, before she could do so, her exile became even more layered. In addition to the complex sense of exile that she was already experiencing, Mary felt the added guilt and angst of a self imposed familial exile. The focus on her studies required a great deal of her time, attention, and energy away from her boys. As a result, she felt, "like I've been neglecting them, because I want to concentrate on school. I'm like all over the place. I'm guilty. I feel guilty when I don't spend time with them but I feel guilty when I don't do my assignments. So, I just need to get it over with."

When Mary noticed that her boys were shy, lacking in confidence, and when it was reported to her that on occasion, if frustrated, her boys retreated to a corner of the classroom "because they didn't understand what they [teacher and/or students] were trying to say," she welcomed the opportunity to enroll them into the Biidaaban Community Service Learning program, specifically the Biidaaban Youth Group. The results were both immediate and progressive.

The Biidaaban Youth Program "was right after school until five," (Tuesday and Thursday) but the boys "didn't mind the extra time in school" in spite of unexpected set-backs. Her oldest son, in his second year at his English school was tested by a psychologist and diagnosed with an intellectual developmental disability. Mary inquired as to the permanency of the disability: "Is he going to grow out of it?" and was told: "No, he's going to have it for the rest of his life." The news was devastating, Mary recalls.

And I was just, I broke down in tears, and all I could think about was the future, like not right now, like it was the future, his future. Like he's not going to want to go to college, all the kids are going to tease him, saying that whatever he's stupid. Girls aren't going to like him; he's going to be with me all the time. But that part I didn't mind. It was just stuff like that.

Mary's narratives revealed that she experienced many forms of adversity, including uprooting, cultural disconnect, linguistic barriers, lack of social integration for herself and her boys, lack of confidence, and embarrassment. But in meeting each adversity she could triumphantly declare: "I overcame it. I'm still a bit there, but I came a long way."

Gradually perseverance and a determination to succeed caused the tide to change for her boys as they continued with the youth group programme. Mary recalls in speaking of her boys 
attending BYG: "I never heard any complaints" and she noticed that they were gaining in linguistic and cultural confidence and that improvement continued and increased their personal confidence to the point where today: "They actually talk to people and they look at them." Mary credits BCSL and its Biidaaban Youth Program for their success: "I just hope that it [BYG] happens more. Like I know that it still does, that it does help, because my kids are more confident and I know that's what helped them."

If we accept Dilthey's (1910) definition of understanding as the process "in which we recognize something inner from the signs that are outwardly given" (p. 329), we can see that Mary's deep understanding of the importance of BYG in the lives of her boys comes from the outward signs that are given. None is more important than her oldest son's reassessment. Mary's recounts the contact that she had with the school.

The school contacted me. They reassessed him. They told me he scored higher, but they didn't clarify what they meant when they said that; so, I got upset again. I was just crazy in my house because I thought it was going to be something worse. I thought well, what if it's autism? I was getting a little ahead of myself. But when I got there, it was because he scored higher in the assessment, and that, it wasn't something more, it wasn't anything worse. It was something, actually an improvement. He doesn't fall under that category [intellectual developmental disability] anymore, he falls under language - something, impairment. So he did improve. They were wrong. In my eyes, they were wrong.

Mary discovered, as Freire $(1970,2000)$ did, that the "word" takes on new meaning. While in the process of learning English as a new language her sons became creators of their own culture. In the linguistic, social, and cultural hybrid of home, of school, of BYG, of new Caucasian friends, of a new spoken language they were able to give names and meaning to things around them, to create their own life-world. The oldest son was especially able to assert himself as an educated person. The English spoken word gave him new power and allowed him to transcend the exile label, to be liberated from the label of oppression that was placed upon him. But it was his mother who recognized that his accomplishments and that of his brother were made possible through the Biidaaban Youth Program: "I'm just glad it was there for them, that it was provided. They needed it!"

\section{"I don't know what they're [BYG] doing, but it works."}

Doris, is a grandmother and Elder who works fulltime for a First Nations' Agency that assists in locating First Nations and Aboriginal newcomers in the community. She and her husband are legal guardians to their granddaughter who always attends the Biidaaban Youth Group Program at her Elementary school. As a matter of fact, Doris reported that, "We rescheduled a vacation because she couldn't miss a class."

Doris experienced the impact of the Biidaaban Youth Group programme vicariously through her granddaughter. This she finds unsatisfactory and laments:

I would love to be on one side of that - a one-way glass or something to actually be able to see it, and maybe even do stuff, you know. Mimic some of the things they do, because sometimes when we try to do homework or do different things it's not the same dynamic.... 
You know, if they saw something that totally discouraged her, or ... something that they thought would work really good with our child, I would love to get an opinion, a letter, a comment, anything from them. Which is sort of, you know, "We observed this..." and "Maybe you could try this..." or "less on phonics and more on, you know, keyboard because she's using an iPad in class." You know, trying the different things. I would love to hear whatever they thought... I think the feedback would be incredible.

It seems clear from Doris' comment that her intentionality in life includes a deep devotion to assisting her granddaughter, who is an identified special needs learner, to achieve her greatest potential in learning and in becoming. One of the impediments to her full engagement and assistance in the learning process of her "child" is a lack of regular communication between the parent and the tutors and leaders in the Biidaaban Youth Group Program.

Despite, being less informed than she would like, Doris has high praise for the Biidaaban Youth Group Program as evidenced in the following excerpts from her interview.

It was actually quite comical in the beginning, because when we first talked about it, she was afraid she was being punished 'cause it was... she heard the word 'homework club,' right, "so I have to do more school work." She didn't know if that was a good idea, and she wasn't too sure, so we talked her into trying it once, and now Tuesday and Thursday just runs our entire family. She just loves it. It's fantastic. It's amazing, the difference it's made for her, and it's a huge positive for her at school, so for us that's something we really appreciate about the Biidaaban Youth Group Program.

I haven't actually watched the program, so I've often wondered what it is they [BYG] do 'cause whenever you pick up your children from school ... what's the first thing you say right? You get in the car: "What did you do? How was it?" You start talking about it right? And we've never had a negative.

What surprised me the most ... [was] just how successful it was. I wasn't that sure that there would be that much of an attachment, or how much it would work. We tried two other programs ... but she didn't attach to them the same way. For some reason this just seems to work for her. I have no idea what the difference is. Maybe it's ... I think attitude is a big part of it. I think that part has made a difference. [S]he doesn't see them as much as, maybe an authority figure, rather as their friends. They view them as their friends. So I think that probably makes a difference too.

... we rescheduled a vacation because she couldn't miss the class.

... we always have the positives, and that's what we want, because some days aren't great for her in the classroom. She's in grade four now; she recognizes that's she's different, you know. She can't write as fast as the rest of them, she can't read as fast as the rest of them. But she felt equal and was always happy at BYG. I guess they're always the star, right when it's one-on-one. There's no too slow, no too fast. It just works. So I think that's the big benefit from a lot of it. I think for kids that are having challenges at school a program like this is phenomenal. 
I'm impressed too by the level of maturity of the placement students and the way they identify with each one of the kids, because each one of them seems to feel like a star. Right? So, you have to be impressed with that, cause everyone's different in one way or another and they seem to get that key thing out of each child, so that's pretty impressive, something to be proud of. Some people try that all their lives and can't pull that off, so it's pretty good.

When I got home that night, I said, "So what do you think of the Biidaaban youth group?" and "So what did you do the last time you were there?" "Well I got chased by some boys." I thought is that a good thing? Oh yeah, no that was a good thing. Haha. I'm not sure what that was about, but.... And then she was saying how they were running around the gym and they were doing stuff. It's all more about the interaction with the group though. "So did you read or do some work?" "Oh yeah that was fine too. That was fine, yeah." It's both group stuff and it's individual, so it would help with the social as well. Everything she talks about it is about a happy thing.

Inherent in the themes of the above excerpts is Doris' preoccupation with responsibility as it impacts her grandchild's emotional welfare. She is very cognizant that her grandchild experiences several challenges in the academic world of the classroom. But in the Biidaaban Youth Group, because of responsibility assumed by the student tutors and student leader, she is accorded equity. The Lithuanian philosopher, Emmanuel Levinas was famous for quoting a remark spoken by Alyosha Karamazov in Fyodor Dostoyevsky's The Brothers Karamazov: "We are all responsible for everyone else - but I am more responsible than all the others" (Levinas, 1989, p. 1). As we listen to Doris' voice as she recounts what she has come to know of the BYG world that her granddaughter inhabits, she opens herself up to us. She is "more responsible than all the others" as she invites us into her world of community. She asks each of us to be like her grandchild, to be honest. Doris perceives that children are honest: "If they don't like something, you'll know. They're not going to play a game; they're not going to be politically correct." We accompany her, step-by-step along the path of discovering her grandchild as she is engaged dialogically one-on-one. She is not equal; she is an individual star shining within the Biidaaban Youth Group galaxy. And, in discovering her, she is inexorably inscribed within us and we assume responsibility for her. We are called by the vulnerability of a child to be responsible to build community with her, with Doris', and with all others, including ourselves, who are now included in her life-world.

Doris is reflective about all the factors that influence and shape the development of her grandchild: the personal, professional, and pedagogical responsibilities of the student tutors and leaders, the positive environment - a secure place, a secure space for every child, the attitude that "it's good to be aboriginal", the seamless awareness of blended cultures, the inter- and intra- relationship developments, the genuine honesty between adult and child, and most importantly, her grandchild's exuberance and seemingly endless happiness. Her grandchild is "a puzzle, pulling all the pieces together to make sure it works." Each piece contributes to Doris' and our "understanding" and acceptance of responsibility within the community of the Biidaaban Youth Group Program for its impact on her child. Doris expresses her heartfelt gratitude for the shared responsibility that has been developed through BYG for and on behalf of her grandchild. 
I'd like to thank whoever had the courage to start tackling this whole thing in the beginning and made it happen, because I know stuff like this doesn't happen overnight. It takes work a lot of work. There's lots of ups and downs, highs and lows, I understand those dynamics. Everyone involved should be extremely proud of themselves and know what a difference they are making in the schools. There will never be enough of Biidaaban Youth Groups in all the schools.

\section{BYG as a value added resource (VAR)}

Bobby is a principal of one of the elementary schools that hosts the Biidaaban Youth Group Program twice a week. During the interview, her stance was not grounded in her lived experiences as much as it was grounded in a critical analysis and appreciation of BYG. As a school administrator, she confessed that she had been envious of other schools in the neighbourhood that have Biidaaban Community Service Learning, specifically the Biidaaban Youth Groups. Additionally, she provides insight into the unique cultural mosaic of her school and she provides valuable insight into the procedural and organizational aspects of BYG as a VAR, or, value added resource, to the school and to the unique blend of First Nations and Aboriginal students within the school.

Our school has traditionally had a significant First Nation component, student population mostly, and being also a dual track school, we would like to think that we are very representative of what the Canadian mosaic is all about, and certainly trying to deepen an understanding of the contributions of the First Nations' culture to society, and having an understanding of their background and their culture and trying to embrace it through the entire school in all aspects of schooling. More specifically, as a leader of the school, recognizing that traditionally there are stigmas still attached to First Nations people and trying to do our part as global citizens to eradicate those misconceptions. I do believe that things have improved in the school system in terms of misconceptions, but they are still out there, and we can't negate the fact that they need to be dealt with. And so, having the Biidaaban Youth Group in our school is an opportunity for our First Nations students to receive additional support and recognize the importance of the support groups that they have in the community and bringing them into the school and valuing them, and celebrating and recognizing what they can contribute to the entire school.

At first, Bobby was uncertain as to what the contribution from BYG would actually be: What would it look like? What would it feel like? Would students connect with the program? Would BYG educationally, socially, recreationally, and culturally be of benefit to her First Nations and Aboriginal students? Not surprisingly, her initial concerns in welcoming BYG into her school were primarily based on custodial responsibilities, ensuring safety and security for each child participating in the programme, parental responsibilities, and the training of the BYG tutors and leaders related to First Nations' and Aboriginal culture. Her concerns also included whether or not BYG personnel could be trusted to keep sensitive information concerning students confidential, and whether they could establish and maintain a communications protocol that would ensure that important information which was time 
sensitive could be shared effectively and efficiently. Bobby explained that many of her early concerns were quickly laid to rest.

I do believe that the people that were recruited for our particular program and our particular sight were excellent role models for our students. At the end of the school day, some of these children are tired and they need an outlet and they need an outlet that is healthy, that is active living-related, but one that has also embedded within it, whether they realize it or not, support in terms of meeting academic needs. And in the case of the students that we, who we worked with, and who the group worked with this year, they brought that sense of need for an educational component into the programme. I think that a testimony to the success of the programme is the fact that many of our students who initially joined the group remained throughout the duration of the programme.

Bobby admits that the inclusion of BYG into her school has been a "growing experience with growing pains" but the positives for the students far outweigh any negatives. Her hope in moving forward is that "more youth groups, like BYG can be incorporated into the fabric of schooling for all the student population," and include programmes that are judged on their merit and not constrained by statistical enrollment or other bureaucratic barriers; programmes including an expansion of BYG to include "buddies" and programmes that conjoin First Nations, Aboriginal and Caucasian students.

The Biidaaban Youth Group Program has contributed much to her school. The university student tutors and leaders have a strong sense of First Nations' and Aboriginal culture and as a result are able to provide a seamless support for the school and for families. They serve as positive role models and model for students participating in BYG the benefits of realizing educational goals or aspirations. This is a significant benefit of BYG, for not only does it provide each student with a safe place and a safe space, but it also provides strong social development for the children. This is especially beneficial to children who are shy or introverted because BYG has given them the confidence to find their voice and to have it heard in a respectful and equitable manner. There is no direct cost to the students to participate in BYG. This is a major benefit to new families who arrive in a transitional state, struggling with the challenges of uprooting from their communities and re-establishing in a new community and educational environment for both parents and children. In this principal's view, BYG as a strong community partner offers a valuable avenue or way in for families to feel connected to the community. BYG goes a long way, as a resource within the school, to reducing or eradicating stressors within families. It provides an incentive for parents and children to remain connected to school.

As Bobby explained, one of her biggest challenges is in assisting families, who arrive after the school year has begun, to feel welcome and comfortable in placing their children in her school and the Biidaaban Youth Groups figure prominently in providing that comfort and assurance.

So when they come to us, we, when they come to us in September, we try to be able to connect them with different things, and it's nice to be able to say, "Well we have a youth group in our school." You know, it's "Oh, really?", and then they'll ask questions about it or 
we'll tell them, you know, we do a fall gathering and we do our powwow, that sort of thing. So, "really?" Or they'll look at some of the projects we do. And they say, "Oh, you know what?" They really do value, you know, our cultural contribution, our presence in the school.

Finally, for Bobby, and her school, BYG enhances the value of First Nations' and Aboriginal culture. Parents view this and see their values reflected in all aspects of schooling and perceive that their presence in the school, their culture in the programmes of the school and their contribution to the school community are valued and incorporated in a meaningful way through all the school's resources of which BYG is integral. Parents see all these factors at work for the benefit of their child or children and therefore, they determine that "this is a good school!"

\section{“Too much; it's too much fun!"}

When Alex, who is nine years old and a child participant in the BYG, talks about the program, her language is affectively rich with enthusiasm and excitement for the program; it's all she can do to contain her exuberance. The most common statements that Alex uses to describe her personal experience with Biidaaban Youth Group contain the word "fun": "It's really fun." "It was so fun." "It's really fun when ...". In their simplicity, Alex's phrases contain a complexity of meaning that mirrors the happiness, the fulfillment, and the sheer joy that is hers in being associated with the Biidaaban Youth Group. But, Alex admits when she first thought of enrolling in BYG, she was concerned about several things.

I wondered what is the coach going to be like. I wondered where it's going to be. I wondered what other kids would be there. It was really cool actually, and I wondered if we were going to do arts and crafts there. And I didn't know that to have an actual snack there. I just thought we were just going to have fun and play. I thought it would be like, I thought it would be like... I can't remember; like older people than teenagers.

But those fears soon disappeared and were replaced by playing board games, making crafts, reading stories, going to the computer lab, playing on the trampoline in the gymnasium, having scavenger hunts in the library, and finally, having a snack - "the snack was bonus!" Alex is quick to point out what she most enjoyed about BYG was that, "you get to do your homework at the Biidaaban Youth Group, and you get it done early." Later in the interview, Alex expanded on the work ethic and reward process that is integral to the success of BYG.

First we work; then we play! We would always get our homework done, and then we would play some games, and we'll do arts and crafts and then we'll do some games in the gym or play a game in the library.

She recognizes that she is challenged in her reading and math skills; but, the various methods used in BYG, such as role reversal, allow Alex to be the teacher and her tutor to be the student. In "a private, quieter space ... because no one is staring at me," Alex teaches her student how to read loudly or softly depending upon what's happening in the story. BYG also makes use of the computer lab and as Alex reports: 
I go on 'mathgames' and there's a crazy taxi game that teaches you how to add and subtract." And, I like reading books, and sometimes [I] go on 'tumblebooks' and we get to read Robert Munsch and lots of illustrators. It's awesome. And sometimes it reads to you or you can read it.

Alex is convinced that "Biidaaban helped me to learn to read harder books. Now I can read chapter books" and she is "happier" because of it. Even though Alex is a child who has identified academic learning needs, she is very positive and finds happiness and enjoyment in everything that she does within the Biidaaban Youth Group including getting her homework done early, improving in her reading, and especially playing games.

It's really fun umm when umm cause Rick, he, he when we were playing hide and go seek, I can't believe actually he did this, but he standed up, and he had a book. He had a book, going like this and he was hiding behind the book. I was like "I can see you". It was funny.

More than the fun and the humor in playing games with Rick, her university tutor, Alex has discovered the joy and happiness that pedagogical love can bring into the life of a child. From a philosophical and pedagogical point of view, it is absolutely essential that a teacher be personally and professionally predisposed to loving children in their present circumstance and to loving the potential of becoming that resides within each of them. This is the essence of pedagogical love. Pedagogical love is a natural way with children; it is not based on sentimentality but on mutual respect. It is a love that embraces all children (Korczak, 1997). Just as not all children within a family require the same parenting at the same time, so, too, children in a classroom do not require the same attention or affection at the same time. It is essential that the teacher gauge the needs of each child. To accomplish this task the teacher must have a relational knowledge of the child, a familiarity with the child's home environment and an understanding of the importance of an inclusive school environment. When taken together, this information can assist the teacher to ensure the welfare of each child and can provide the teacher with ample direction concerning the timing and appropriateness of teacher-initiated affection or action toward a child.

A heightened sense of efficacy, a reinforced belief in personal value, a life-long improvement in literacy skills, and, a deep sense of belonging within the "private, quieter, [inner] space" of the Biidaaban Youth Group are the positives that scaffold Alex's happiness. The relaxed and fostering environment of Biidaaban where "nobody is staring at me" helps to address the vulnerability of childhood in Alex and evokes from her the latent possibility and potential to become all that she can be. It's not surprising, that when asked by her Nana, "So, how come I'm never allowed to pick you up early?" Alex immediately replies, "Because it's too much fun!"

\section{'You know what? You don't understand who I am. You don't know my background.'}

When Sarah, a criminology-sociology major at the university, entered the Biidaaban Community Service Learning Program and became associated with the Biidaaban Youth Group, she did so at the suggestion of one of her sociology professors urging her to consider completing a CSL placement as part of her course. At first, Sarah had misgivings about 
working with First Nation and Aboriginal children in a quasi-teaching role. She was not in the teacher education program so she felt that she lacked the requisite training and she was distinctly "very white middle class" and felt that because of the cultural barriers, the language barriers, and the social barriers, "I wasn't going to relate to them in a way that would benefit their learning, because we had come from such different experiences". From her comments, it was obvious that Sarah was focused on Other rather than her-Self. In her orientation to Other, Sarah evidences a deep sense of responsibility, a responsibility irrefutable and ever compelling and one that Levinas (1994) explicates as never ending.

One's duty regarding the other who makes appeal to one's responsibility is an investing of one's freedom. In responsibility, which is, as such, irrecusable and non-transferable, I am instituted as non-interchangeable: I am chosen as unique and incomparable. My freedom and my rights, before manifesting themselves in my opposition to the freedom and rights of the other person, will manifest themselves precisely in the form of responsibility, in human fraternity. An inexhaustible responsibility: for with the other our accounts are never settled. (p. 125)

A theme that runs throughout Sarah's discourse is her deep sense of responsibility and commitment to the welfare of Other.

I was worried that our value systems would differ, you know. It concerned me because ... I didn't want to make the children feel uncomfortable around me. I was worried that the games I grew up with, or the activities that I was familiar with, would not be the same as theirs.

A dominant theme in Sarah's discourse is a serious concern that her intentionality, relationality, and responsible actions with the children could be perceived by all involved with the Biidaaban Youth Group as profoundly just and ethical. As a consequence, when she entered the Biidaaban Your Group for the first time, she was anxious about her potential to contribute.

I was kind of really nervous, and I was trying to address the children by names and ... they were really receptive. I had a little girl, she came right up to me and gave me a big hug, and she was like 'Hi', and I was uncomfortable a little bit because I thought, 'Oh my goodness, you know, is this appropriate or not appropriate?' but she made me feel welcome, you know?

That act of welcoming solidified for Sarah her compulsion to interact with the children on a platform of "openness": "I was open to who they were and what they had to say and they were open to me and to what I had to say ... and they accepted me and I accepted them".

Gadamer (1989) explains that this understanding of Other is not sympathy (feeling for) or empathy (feeling with), for within the Other there is a recognition of some part of our Self ( $p$. 305). Furthermore, Gadamer contends that there exists a split between traditions, cultures, and people that cannot be spliced; we cannot ever sufficiently free our Self from personal prejudices and/or biases to apprehend fully the meaning of Other or become the Other. However, in building on Hegel's notion of "bildung", Gadamer defines bildung as: 
...keeping oneself open to what is other - to other, more universal points of view. It embraces a sense of proportion and distance in relation to itself, and hence consists in rising above itself to universality. To distance oneself from oneself and from one's private purposes means to look at these in the way that others see them. ... thus the cultivate consciousness has in fact more the character of sense. For every sense ... is already universal in that it embraces its sphere, remains open to a particular field and grasps the distinctiveness within what is opened to it in this way. (pp. 14-15)

While we agree with Gadamer, that Self can never become Other, Sarah's openness to the children and her inherent sense of Other cultivates a consciousness of Other and demonstrates an ability and a capacity to accommodate Other as Self. In this respect, Sarah succeeds in bridging the gap of traditions, culture, and differences in people to conjoin Self with Other. In effect, her innate sense of opening herself up to an accommodation of the vulnerable Other of child and her sense of allowing the vulnerability of her Self to be exposed to and accommodated by the Other of child transcends the great divide between Self and Other that Gadamer describes, and enables her to achieve attention to the pathic (Hatt, 2008).

\section{Discussion: Pathic Teaching and the Value of Service as a Liberatory Learning Experience for those who Serve}

Attending is an active, not a passive, verb and in the case of education, it demands an intended, or intentional, pedagogical action on the part of the tutor toward his/her student. Pathic teaching (van Manen, 1999) requires a deliberate or intentional felt understanding of ourselves as educators, and of our students as Other(s), in each learning situation. The pathic is not an event. It is an experience of felt response and is a topic that is best explored sensitively through inquiry and reflection.

Pathic, like empathy and sympathy, etymologically finds its base in the Greek pathy or pathia meaning affection, passion or feeling for disease and suffering (Klein, 1967, p. 1139) and is closely associated with pathos, another word stemming from the same root, and meaning the "quality which arouses pity or sorrow" (p. 1139). In the larger context of lived experience, pathic refers to the felt emotion, the receptivity of mood, and the shared sensibility of being in the world as One and as Other. If we want to more fully understand the pathic we must attend to how it presents itself in life by Others; by those who live it. The pathic cannot be perceived, nor received, in an educational world in which feeling for an Other or the emotive state of being is absent or marginalized (van Manen, 1999). It must be recognized that within the relationality of human beings, as between an adult or child, there is an implicit felt understanding, a Gadamer 'sense', of themselves and others. The pathic is characterized by a movement away from Self, as One, toward a full accommodation of the self of the student, as Other.

Sarah epitomizes the process of journey rather than destination in the learning that shapes her and which has a profound effect on her ability to accommodate Other as self. The process is not linear; rather, it rises and falls through discourse and lived experiences that result in cognitive and non-cognitive shaping of meaning-making and personal perceptions of Self and Other. Her journey toward attending the pathic follows a path similar to that of 
transformative learning (Mezirow, 2000, 2009) and the phases of meaning-making and making personal understanding of issues or beliefs, through assessing the evidence and arguments of a point of view or issue, and being open to looking at alternative points of view, or alternative beliefs, then reflecting critically on the new information, and making a personal judgment based on a new assessment of the information. Transformation often follows a variation of the following phases of clarification:

- a disorienting dilemma - loss of job, divorce, marriage, back to school, or moving to a new culture;

- $\quad$ self-examination with feelings of fear, anger, guilt, or shame;

- a critical assessment of assumptions;

- recognition that one's discontent and the process of transformation are shared;

- exploration of options for new roles, relationships and actions;

- planning a course of action;

- acquiring knowledge and skills for implementing one's plans;

- provisional trying of new roles;

- building competence and self-confidence in new roles and relationships; and

- a reintegration into one's life on the basis of conditions dictated by one's new perspective. (pp. 19 - 22)

Examination of the data provided by Sarah in gives ample evidence of the transformation that is and has taken place within her Self through attending the pathic in Other(s). By way of specifics, and as presented above, Sarah, experienced disorientation of Self as she entered the life-world of the Biidaaban Youth Group. Her immediate response was to engage in a critical examination of her Self - her feelings of fear, guilt, shame: "because I was very middle class, I'm part of, I guess, what we would consider the dominant society, or the majority.... So, I was worried that our value systems would differ, you know."

Before she can grasp the full extent of her "critical assessment of assumptions," Sarah was thrust into a situation where her ideas respecting activities that she felt would be engaging for BYG students were given passing attention if not dismissed outright. She was left with the unmistakable impression that her peers (tutors who were university students in the consecutive education program) were the education experts and they would plan the activity and Sarah would carry it out. Sarah experienced a double dose of exile when she was alienated by a group of parents. Her reaction wass a mixture of injured pride and hostility.

It was devastating. I mean you feel alone. It was uh... a terrible feeling, and you feel there's a helplessness and a normlessness that goes with it because you really don't feel like approaching anybody for help because you're not sure that anybody, that people are going to respond to you in a positive way. And I had never experienced that before. You know, they saw me as white middle class, educated, and probably that very cookie cutter type girl. I was 
girly. I fit the mold I guess, for lack of a better term. I was defensive, and I thought, 'You know what, you don't understand who I am. You don't know my background.' And it was funny, because I had been told those things by them. I felt like this particular group of parents were... just didn't understand, and I thought how dare you question my motives, I'm here as a volunteer, I'm helping your children, you know? So yeah, so at first I was, I was defensive and I think I probably went through a week of that, where I did my programs with the children, and I really didn't stick around after the program to talk to the parents, because I thought 'I don't, I don't need this. This is stress for me, I don't need it.' And that just made things worse, because then it looked like I was really being ignorant.

In the process of planning a course of action, Sarah was befriended by one of the parents who identified her suffering and sought to address it. As Sarah talked to the parent she began to recognize that her discontent and the process of transformation that she was experiencing were also shared by a number of the parents.

I had spoken to one of the parents that befriended me on the reservation. She was very nice. And she said, 'You know what, give them time. You know, they're learning too, like you're learning, they're learning, and this was a new experience for them.' And I said, 'Well this is a new experience for me too.' And she said, 'But you know what, you don't, you will never get anywhere if you walk into this situation with a hostile attitude.' And I thought, 'What a great piece of advice.'

As Sarah gained new knowledge and understanding of her Self, as she adopted a new role for dealing with challenges, as she developed and honed new skills of discourse and communication, she built competence in her Self and self-confidence in her new roles and relationships.

... I know that by me not coming to the peer tutoring group every week with that hostile attitude, even if I was upset, it paid off in the end, you know, to kind of reserve that impulse to just get angry. Yeah, yeah, so it made things much more I guess fluid in terms of talking and education. And you know what, we made a lot better progress when I didn't walk in with a bad attitude.

We would argue that the key to Sarah's transformation to her reintegration of Self into a new life based on the conditions of her new perspective was always her deep commitment to pedagogical love and through that love and attending to the pathic in the Other of each child she related to, and who related to her.

The kids and I interacted very well; [the tutors] weren't so talkative with the students, but they recognized that I had that, that connection with them. I was very open to what they had to say, and I liked that they were so open with me. I would question them instead of always telling them or instructing them on how to do something. I think our connection really opened up because I thought, I need to step back and let them show me how this activity is supposed to run. I can plan the activity, but they really want to make it their own, you know? And that's okay, it's ... it's okay. 
By the end of the program, Sarah's students and their parents had come to recognize that her greatest strength was her unconditional love for each child and her willingness to engage in one-on-one relational discourse.

The more I interacted with this one kid, the more fascinating I thought he was because he was, he wasn't very good at speaking English, but he was able to draw too, they're all good drawers, and he would draw me, we'd draw pictures together and then he would tell me things about my picture that didn't even come into my mind.

One of the strongest reoccurring themes in Sarah's discourse wass her emphasis on trust with the children: "I feel that before I can reach any student, I have to have some relationship with that student. There has to be trust between us." The theorist van Manen (1991) reinforces Sarah's belief in the power of trust: "Trust enables! Trustful hope is our experience of the child's possibilities and development" (p. 68). Children who experience the enabling influence of trust through pedagogical love are encouraged to have trust in themselves. Sarah instinctively senses the importance of trust and understands how to inculcate trust in her relationality with her students.

I noticed one of the other peer tutors was like 'no, no, stop that. Colour inside the lines, and use this colour' and she was more instructing her, and this little girl really wasn't responsive to that so I, I kind of snuggled up to her and I said. 'What are you doing?' She says, 'Oh I'm writing numbers'. I said, 'Well, yeah why, why are you writing numbers?' And she goes, 'Well I really like numbers. I'm trying to learn how to count.' And I said 'Oh', I said, 'Oh I can help you count.' She goes, 'Yeah?' And I said, 'Yeah!' And she goes, 'Well I'm supposed to colour in the lines.' I said, 'Well no, that's okay. We can colour it in with numbers you know?' and I thought instead of having somebody talk at her and say 'stop that', find out why she's, she's drawing these numbers and it was, she was trying to learn how to count better. And I thought, that, that's incredible.

Through personal interactions, Sarah illustrates that the instructional process "is constantly conditioned by personal, relational, intentional, and contingent factors that make teaching possible in the first place" (van Manen \& Li, 2002, p. 217). She established an inclusive environment within the Biidaaban Youth Group that highlighted the relationship that existed between her and her students. In her tutoring, love was the condition of pedagogy and the precondition for the pedagogical relationship. Such a relationship, in her view, is absolutely essential to the growth of her students as mature, responsible individuals. Sarah realizes that in order for a child to maximize understanding and knowledge, there must be a harmonizing in student learning of the cognitive (the gnostic, or the head) and of the non-cognitive (the pathic, or the heart).

If we, like Sarah, are truly committed to educating the whole child, then we must recognize that neither the head nor the heart is dominant in the body. Both are essential in balancing the dimensions of intellectual being, living, and visceral knowing. Without carefully attending the pathic we cannot fully attend the heart in teaching. But, as Sarah attended the pathic in Other as Self, she also grew in maturity, understanding, and responsibility. She was intimately engaged in a process of transformational learning; she was deeply engaged in 
attending the pathic, in accommodating the Other as self, and as these two parallel processes conjoined, Sarah is able to extend her self-actualization into the realm of "peak experiences" (Maslow, 1970).

Peak experiences, are intense effective and affective experiences that leave an individual and her/his perception of Self forever altered, usually becoming more cognitively and non-cognitively healthy. Peak experiences, in the positive effect, are usually of short duration but the accompanying positive affect is usually long lasting. Peak experiences teach the individual that:

The universe is ultimately good or neutral, not evil; that the ultimate good is composed of Being-values such as truth, goodness, wholeness, beauty, dichotomy-transcendence, aliveness, uniqueness, perfection, necessity, completion, justice, order, simplicity, richness, effortlessness, playfulness, and self-sufficiency; and that opposites really do not exist. (Mathes, et al., 1982, p. 93)

Daloz (1986) recognized that growth can be a risky and frightening journey into the unknown, as the individual is challenged to let go of old conceptualizations of Self and their customized life-world. Sarah has been simultaneously involved in a dual process that has resulted in a reformation of her structures for meaning making. She has had to reconstruct the dominant narratives or stories of her life to fit a new perception of her life-world. The catalyst of reformation in each instance has been a child: whether it was a child who introduced her to the power of imagination creativity education in discovering a unique way of learning numbers; or, whether it was the child who introduced her to the cathartic and liberating power of genuine hugs, because those hugs were "just love. It was just love and it was acceptance;" or, whether it was the child who introduced her to a deep and insightful perception of visual imagery in her drawings; or, whether it was the child who introduced her to the ecstasy of "a plate of goose hearts;" or, whether it was the two children who rushed up to her in the Walmart while she was in the midst of a life-crises: “... and gave me a hug and they were like, 'Oh my goodness, you know we missed you last week'. "And uh... they hugged me and Steven looked up to me, he had had particular issues with his mother, his biological mother, and he was under the care of either his aunt or his grandmother most of the time, and uh, he gave me a big hug, and he just kind of looked up at me and he said, 'I wish you were my mom"'; or, finally, whether it was the child who helped her through a traumatic moment of insecurity and turmoil.

I went to the Biidaaban Youth Group the day after I found out that I had breast cancer, and one of the little girls was combing my hair, she was brushing my hair because we were playing dress-up. And I started to cry because I was worried that if I selected chemo as my treatment, I was going to lose my hair, which is precious to a girl. So I was very upset and she ran and got the Kleenex box and umm... she gave me some Kleenex, so I dried my tears, I'm like, 'Oh I'm sorry.' And she's like, 'Did I hurt you?' And I said, 'No, no'. And then she said, 'Oh don't cry', and she put my hair in a ponytail and she put a hat on like a tuque and then I started to cry more because I thought this is what I'm going to look like. This is what's going to happen. And uh, she brought me, she showed me in the mirror and she said, 'I think 
you still look pretty.' I just broke down because that was all I needed. I didn't think it was going to come from a little person. But in that moment I really needed somebody to just reassure me that it was going to be okay, and that it didn't matter if I had hair or not, and it didn't matter if I was sick, because when I came home that day I felt like, that I could do it, that I didn't need to be so insecure, I didn't need to be unconfident because I wasn't losing anything. I hadn't lost anything yet at this point and I should just enjoy myself as I am, because people will see past whether I have hair or not, whether I have a disease or not, and it was great, it was a great moment.

Peak experiences, as Sarah demonstrated, require a reformation of meaning-making structures in our lives but, when accomplished, result in moments of intense joy, wonder, awe, and ecstasy. Even simple experiences were, for Sarah, a continual source of inspiration and pleasure. Each experience enlarged her, and Sarah was left feeling inspired, strengthened, and renewed. As she questioned her own point of view, as she reflected upon and incorporated alternate points of view into her restructured world-view, she was inspirited and she succeeded in attaining a liberatory education in respect of community service-learning. Chambers (2009) contends that, "within the liberatory education paradigm, social change begins when individuals develop a clearer sense of their own values, of their concerns for a more equitable society, and of their willingness to support others in various communities" ( $p$. $84)$.

\section{Conclusions}

One of the most effective methods of teaching is by example or model. Sarah modeled her dual focus on the cognitive and the non-cognitive in the pedagogical relationships that she established with the children in the Biidaaban Youth Group. She engaged her students in highly interactive and enabling activities; she guided them in taking note of the salient points that would extend their learning; she coached them to reflect on their learning and inspired them toward further learning. She spent high quality time developing and maintaining a personal relationship with each of her students and she looked for occasions to extend learning opportunities in pathic one-to-one interactions.

Increasingly, classroom teachers are required to evaluate their teaching in technical, rational, or corporate terms of outcomes, efficiency, and accountability. There is little or no time allocated to teachers to respond, reflect, or reconstruct their thinking on the meaning, purpose, and significance of pedagogical relationships. In the midst of educational restrictions, the challenge for most teachers is to remember poignantly their pedagogical orientation to each child. Love, hope, and responsibility from the adult to the child are the conditions of pedagogical orientation (van Manen, 1991, p. 123) and these in turn create the context for liberatory service. Ideally, the school and the official curriculum should serve the unique needs of every child, which is a frequently stated purpose of curriculum.

The Biidaaban Community Service-Learning program offers an opportunity through the Biidaaban Youth Group to focus on the unique needs of each child. The themes, concepts and ideations expressed by Mary, Doris, Bobby, Alex, and Sarah bear witness and testimony to the powerful influence for good that BYG has had in their lives and in the lives of the 
children the program has been privileged to touch. Greene (1995) contends that the point of meaning-making is to: "order experiences in such a fashion as to move diverse persons to mindfulness and to care ... [and to make] connection between diversely lived experiences and an increasingly meaningful world" (pp. $142 \& 144$ ). The establishment of relationships that support positive learning and positive experiences are essential and the BYG presents a voluntary opportunity for parents and children to join together with university students, community leaders and the university community and experience this level of success.

The enactive presence of pedagogical love incorporated by Sarah into all her activities encouraged students to make meaning for Self and Other rather than to find meaning beyond themselves in an externally prescribed life-world. Respect, trust, and unconditional love are the essential principles within the Biidaaban Youth Group that consistently equip students with the competence and confidence to trump "the uncontrollable stuff of desire, fear, horror, pleasure, power, anxiety, fantasy, and the unthinkable" (Ellsworth, 1997, p. 46). Aoki (1993) contends that these qualities are not extraordinary or unusual, but must be viewed as common within young people (p. 283), especially within the age group that Biidaaban targets.

Oscillation between understanding and misunderstanding occurs in student learning and knowing and is often a result of the flux of emotions, attention, and interest within an individual student or within students collectively. Every student, as child, is unique and exhibits: "inclination, sensitivities, modalities of being which soon express themselves in certain choices, interests, and desires" (van Manen, 1991, p. 19). Acceptance of the Other in each student in the enactive and relational development of Self is paramount in the interaction and exchange between teacher and student at every level of instruction. Sarah teaches us that her peak experiences while assisting students to make personal meaning of issues or beliefs, involve a process of understanding and assessing the evidence and arguments of a point of view or issue, and being open to looking at alternative points of view of Other, or alternative beliefs of Self, then reflecting critically on the new information, and making a personal judgement based on a new assessment of the information. This is the essence of liberatory service learning (Chambers, 2009). In recounting her personal lived experience(s) with Biidaaban Youth Program, Sarah provides the rationale for her inspirited success in attaining a liberatory education in respect of community service-learning.

I was so fortunate, because there was not one day that I walked onto the tutoring scene, where I didn't experience something different, or I didn't have an experience that didn't touch my heart in some way. I always left the Biidaaban Youth Group feeling successful. Like either I had taught the children something or they had taught me something, and I'm just, I'm completely enlightened, completely. Yeah, and it's been a 180 degree shift with the way I perceive things and the way that I interact with other people, because I've got all these skills that I never, or maybe I had them before but they weren't developed, but they are now. I have so much passion now for things that I never used to, and it's made my life so much better. And, I've brought that passion to my education, because I'm starting to realize that, when you put something like that into everything, you can go home and feel so much pride and success in who you are. And I think that's been the best thing for me, is just finding out who I am and being reassured of who I am and being accepted for who I am. It really showed me that I 
don't have to put on all those masks every time I'm in a different situation. I can just wear one mask and that's okay. I don't have to just be a student, or just be a daughter, or just be an employee somewhere. I can be Sarah and I can be okay with that, you know? It shouldn't... the situation should not change who I am. I should be changing the situation because of who I am. And I thought... that's what those kids gave me, you know, and we're talking six to twelve year olds, and it's been amazing.

\section{Limitations}

One of the limitations of this study is that it was focused on one community service-learning programme and involved a limited number of participants associated with that programme. Another limitation is that three of the five participants interviewed in this study were limited in their personal association with the programme; they were telling the stories of others who had first hand experience. Their perspectives as revealed in their interviews, while grounded in evidentiary themes of custodial responsibility, caring, and compassion, are decidedly extrospective. As a consequence, their involvement while providing a unique and valuable commentary on BYG points to the need for further expansion of this study and a need to examine more views of those who serve and those who are served by the programme. This personalized examination of the impact of the program as a service has provided a way to enrich the information that we know from the annual reports that are part of the current programme reporting mechanisms.

\section{References}

Astin, A.W., \& Sax, L.J. (1998). How undergraduates are affected by service learning. Journal of College Student Development, 39(3), 251-263.

Bandura, A. (1977). Social learning theory. Englewood Cliffs, NJ: Prentice Hall.

Bringle, R.G., \& Hatcher, J.A. (1996). Implementing service learning in higher education. Journal of Higher Education, 67(2), 221-239. https://doi.org/10.2307/2943981

Buber, M. (1970). I and Thou. Trans. W. Kaufmann. New York: Simon \& Shuster.

Chambers, T. (2009). A continuum of approaches to service-learning within Canadian post-secondary education. Canadian Journal of Higher Education, 59(2), 77-100.

Cottle, T. J. (2003). A sense of self: The work of affirmation. Amherst, MA: University of Massachusetts Press.

Dilthey, W. (1910, 2002). The understanding of other persons and their manifestations of life. Selected works, vol iii: The formation of the historical world in the human sciences. Eds. R. A. Makkreel \& F. Rodi. Princeton, NJ: Princeton University Press, pp. 226-247.

Dilthey, W. (1910, 2002). Appendix. Selected works, vol iii: The formation of the historical world in the human sciences. Eds. R. A. Makkreel \& F. Rodi. Princeton, NJ: Princeton University Press, pp. 315-368. 
Ethington, C. A., \& horn, R. A. (2007). An examination of Pace's model of student development and college impress. Community College Journal of Research and Practice, 31(3), 183-198. https://doi.org/10.1080/10668920600857222

Freire, P. (1970, 2000). Pedagogy of the oppressed: $30^{\text {th }}$ anniversary edition. Trans. M. Bergman Ramos. New York: Continuum.

Green, M., Eckel, P., \& Hill, B. (1998). On change: In route to transformation. (An occasional paper series of the ACE project on leadership and institutional transformation). Washington, DC: American Council on Education.

Hatt, B. E. (2008). Heart in teaching: Attending the pathic. Kohn, DE: Lambert Academic Press.

Heidegger, M. (1996). Being and time. Trans. J. Stambough. New York: SUNY Press.

Kvale, S. (1996). InterViews: An introduction to qualitative research interviewing. Thousand Oaks, CA: Sage.

Levinas, E. (1989). The Levinas reader. Ed. S. Hand. Oxford, UK: Blackwell.

Levinas, E. (1994). Outside the subject. Trans. M B. Smith. Stanford: Stanford University Press.

Maslow, A. (1964). Religions, values and peak experiences. Columbus: Ohio State University Press.

Maynes, N., Hatt, B.E., \& Wideman, R. (2011). Service learning as an alternative practicum experience in a pre-service education program. Canadian Journal of Higher Education, 43(1), 80-99.

Noddings, N. (1984). Caring: A feminine approach to ethics and moral education. Berkeley: University of California Press.

Pace, C. R. (1979). Measuring outcomes of college: Fifty years of findings and recommendations for the future. San Francisco: Jossey-Bass.

Pace, C. R. (1984). Measuring the quality of college student experiences: An account of the development and use of the college student experiences questionnaire. Los Angeles: University of California, Graduate School of Education, Higher Education Research Institute.

Reardon, K.M. (1998). Participatory action research as RSL. New Directions for Teaching and Learning, 73, 37-44.

Schubert, W. H. (2010). Language, legacy and love in curriculum. Curriculum and Teaching Dialogue, 12(1-2), 1-23.

Schutz, A., \& Ruggles, A. (1998). RSL and English studies: Rethinking "public" service. College English, 60(2), 214-223. https://doi.org/10.2307/378323 
Strauss, A., \& Corbin, J. (1998). Basics of qualitative research. $\left(2^{\text {nd }}\right.$ Ed.). Thousand Oaks, CA: Sage.

Van Manen, M. (1997). Researching lived experience: Human science for an action sensitive pedagogy. Toronto: House of Anansi Press.

VanWynsberghe, R., \& Andruske, C.L. (2007). Research in the service of co learning: Sustainability and community engagement. Canadian Journal of Education, 30(1), 349-376. https://doi.org/10.2307/20466638

Weinberg, A.S. (2003). Negotiating community based research: A case study of the "Life's Work" project. Michigan Journal of Community Service-Learning, 26-35.

Wiechman, M.C. (1996). Investigating urban community needs: RSL from a social justice perspective. Education and Urban Society, 28(2), 224-236. https://doi.org/10.1177/0013124596028002007 